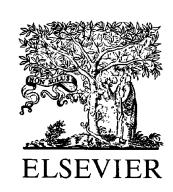

\title{
Local Immunosuppression in Clinical Small Bowel Transplantation (Report of Two Cases)
}

\author{
A. Furtado, R. Perdigoto, F. Oliveira, B. Geraldes, E. Furtado, L. Tomé, O. Mota, J. Ferrão, J. Viana, \\ C. Bento, H. Vieira, and S. Neves
}

$\mathrm{L}^{\mathrm{c}}$ OCAL IMMUNOSUPPRESSION (L-IMS) has been used for many years, ${ }^{1}$ particularly in animal experimental organ transplantation. It has also been used in human kidney transplantation. ${ }^{2}$ The rationale for this practice is that the most important immunologic events leading to rejection occur in the graft. For instance, it has been demonstrated that local expansion of donor-specific $\mathrm{T}$ cells may mediate graft rejection after the first posttransplant days, without the participation of the circulating pool of lymphocytes. ${ }^{1}$ Thus, it should be expected that local intraarterial delivery of the immunosuppressive agents reaches higher levels of efficacy for the same doses or even for lower doses than when they are systemically administered.

To our knowledge, despite the encouraging results of many experimental studies, no clinical use of L-IMS has yet been carried out in human organ transplantation, with the exception of some data from the 1960s.

Small bowel transplantation (SBTx) still carries a high incidence of severe cellular rejection, with serious and devastating consequences. Faced with two particularly difficult patients, the present investigators used L-IMS for several weeks posttransplantation, with lower doses of immunosuppressive drugs and obvious success. These two cases and the technique of L-IMS are reported herein.

\section{PATIENTS AND METHODS}

\section{Patient 1}

The first patient (S.A.F.S.), an 18-year-old boy, lost the fourth portion of the duodenum, the whole small bowel, and the right colon following a complete volvulus procedure on September 30, 1994; 10 days later he was admitted to our department for evaluation. He had a wide duodenostomy in the upper left quadrant of the abdomen, and his weight was $52 \mathrm{~kg}$ and height $1.8 \mathrm{~m}$; routine laboratory values were normal as well as chest X-rays, ECG, and liver and respiratory functional tests. Abdominal Doppler ultrasound and aortography showed no superior mesenteric artery. A long-term central venous catheter was placed for total parenteral nutrition at home (THPN). Four months later, he had gained $18 \mathrm{~kg}$. Later he experienced several catheter-related infections, which led to the replacement of the catheter. At the end of the second year, he developed chronic cholestasis with advanced liver fibrosis. An extremely severe episode of bacterial and fungal sepsis prompted his admission to the ICU. During 1 month, this situation proved to be resistant to all treatments. In spite of this, we performed a combined liver and SBTx (LSBTx). Prothrombin time was 5 seconds above control and total bilirubin was $36.8 \mathrm{mg} / \mathrm{dL}$. The donor was a young man, ABO-compatible, with no HLA match. Procurement and transplantation were performed according to established rules.

Immunosuppression was based on intravenous tacrolimus, 0.02 to $0.12 \mathrm{mg} / \mathrm{kg}$ per day (total bilirubin levels 12 to $40 \mathrm{ng} / \mathrm{mL}$ for the first 2 weeks, then 12 to $20 \mathrm{ng} / \mathrm{mL}$ ); methylprednisolone initially as two "bolus" injections of $250 \mathrm{mg}$, tapered to $20 \mathrm{mg} / \mathrm{d}$ by the end of the first month; and azathioprine as a single dose of $2 \mathrm{mg} / \mathrm{kg}$. Oral selective bowel decontamination, aciclovir, and cotrimoxazol were administered according to routine protocol for our liver transplant patients. Also given were broad-spectrum antibiotics and amphotericin B for 2 weeks, and subsequently when necessary, and prostaglandin $\mathrm{E}_{1}$ during the first week. Routine small bowel biopsies were performed every other day for the first 2 weeks, and thereafter whenever indicated. The hepatic graft showed good function from the very beginning and the small bowel returned to normal peristalsis by day 6 . A small bowel biopsy performed at this time showed acute severe cellular rejection, which responded to boluses of steroids and increased levels of tacrolimus. By week 2, severe interstitial pneumonia required urgent mechanical ventilation. Along with intensive antibiotic therapy, immunosuppression was substantially reduced. The patient was free from mechanical ventilation 1 month later, while maintaining sepsis and having lost the bowel graft due to rejection.

The grafted liver maintained good function throughout this period, and at 2 months posttransplant the small bowel graft was removed. At 3 months, a second SBTx was carried out from a cadaveric ABO-identical, two-HLA-match donor. This time, a $15-\mathrm{cm}$ segment of the middle colic artery (MCA) of the donor was isolated continuously with the superior mesenteric artery (SMA) (Fig 1). A very narrow catheter was inserted into the MCA, its tip reaching the emergence of that artery from the SMA.

L-IMS consisted of methylprednisolone and tacrolimus via catheter for 3 weeks (details in Table 1).

There were three episodes of moderate-to-severe acute rejection that responded well to boluses of methylprednisolone and increased doses of tacrolimus. By week 3 of L-IMS the catheter occluded, and oral and intravenous IMS was started. The intraarterial catheter was withdrawn and the distal end of the MCA was

From the Department of Transplantation, HUC, Coimbra, Portugal.

Address reprint requests to Dr A.J. Linhares Furtado, Director do Serviço de Urologia e Transplantação/Hospitais da Universidade de Coimbra, 3049 Coimbra Codex, Portugal. 


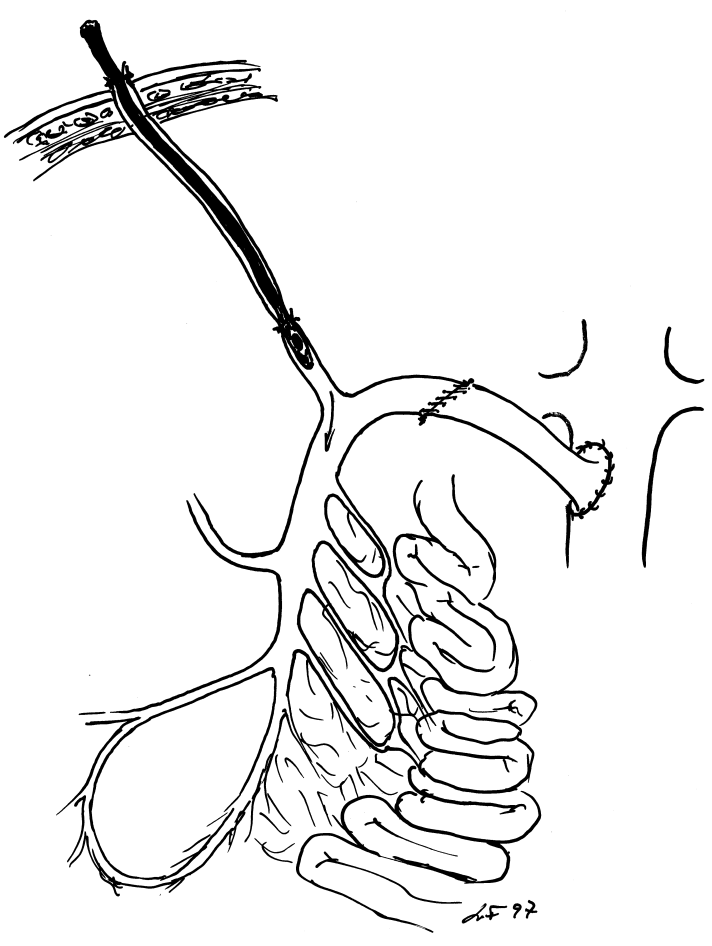

Fig 1. The middle colic artery (MCA) was isolated and kept in continuity with the superior mesenteric artery of the cadaveric intestinal graft. A fine catheter was introduced into the MCA. The distal end of the MCA was sutured to the dermal layer.

ligated. At 3 months after retransplant the patient returned home free from parenteral nutrition. At 32 months he passes four to eight loose stools per day, his weight is stable, and he is able to work.

\section{Patient 2}

The second patient (R.P.L.G.), a 17-year-old boy, lost his small bowel following a volvulus when he was 9 years of age; the remaining $30 \mathrm{~cm}$ of proximal jejunum was anastomosed to the colon. He was on parenteral nutrition and oral intake; catheterrelated infections and thrombosis of venous accesses were the major complications. He had been submitted to a lengthening of the remaining jejunum (Biancchi operation) followed by some improvement in nutrition. However, 1 year later he developed severe hypocalcemia that motivated several hospital admissions and was again put on parenteral nutrition. Growth retardation was striking and loss of venous accesses became a severe complication.

Table 1. Local Immunosuppression for Patient 1

\begin{tabular}{lccc}
\hline $\begin{array}{c}\text { Small Bowel } \\
\text { Retransplant }\end{array}$ & $\begin{array}{c}\text { Tacrolimus } \\
(\mathrm{mg} / \mathrm{kg} \\
\text { per day) }\end{array}$ & $\begin{array}{c}\text { Total Bilirubin } \\
(\mathrm{MEIA}) \\
(\mathrm{ng} / \mathrm{mL})\end{array}$ & Complications \\
\hline Week 1 & 0.12 & 42 & - \\
Week 2 & 0.09 & 38 & - \\
Week 3 & 0.06 & 44 & $\begin{array}{c}\text { End of L-IMS at day 22; } \\
\text { acute rejection at days } \\
\end{array}$ \\
& & & $\begin{array}{l}\text { 18, 25, and 69 } \\
\text { (good response to MP) }\end{array}$ \\
& & &
\end{tabular}

$\mathrm{PGE}_{1} 0.04$ to $0.07 \mathrm{ng} / \mathrm{kg}$ per minute (7 days).
Table 2. Local Immunosuppression for Patient 2

\begin{tabular}{|c|c|c|c|}
\hline & $\begin{array}{l}\text { Tacrolimus } \\
\text { (mg/kg per } \\
\text { day) }\end{array}$ & $\begin{array}{l}\text { Total Bilirubin } \\
\text { (MEIA) (ng/ } \\
\mathrm{mL})\end{array}$ & Complications \\
\hline Week 1 & 0.08 & 46.2 & $\begin{array}{l}\text { Acute rejection (AR) at day } 4 \\
\text { (mild) }\end{array}$ \\
\hline Week 2 & 0.08 & 38.2 & (local methylprednisolone) \\
\hline Week 3 & 0.09 & 36 & \\
\hline Week 4 & 0.05 & 35.5 & AR at day 22 (moderate/severe) \\
\hline Week 5 & 0.05 & 28.8 & (local methylprednisolone) \\
\hline Week 6 & 0.02 & 17.6 & \\
\hline Week 7 & 0.04 & 12.3 & $\begin{array}{l}\text { Severe pneumonia (mechanical } \\
\text { ventilation, } 7 \text { days) }\end{array}$ \\
\hline
\end{tabular}

$\mathrm{PGE}_{1} 0.04$ to $0.07 \mathrm{ng} / \mathrm{kg}$ per minute (7 days).

In the beginning of 1998 he was referred and admitted to our department. He was wheelchair-bound, severely malnourished, and had growth far below normal, with hypoalbuminemia, anemia, hypocalcemia, generalized severe osteoporosis and osteopenia, and some crushed vertebrae. Liver, heart, lung, and kidney functions were normal.

He passed several stools a day that were watery and with rests of recent meals. No venous access was available, with extensive obliteration of both vena cava. A transthoracic venous access to the superior vena cava was then created; highly caloric total parenteral nutrition and physiotherapy were started. Weight gain was very slight after 4 months, although some improvements were seen, in particular the disappearance of muscle spasms.

In September 1998 he received a small bowel graft from a cadaveric, ABO-identical, total HLA-mismatched donor. The ileocecal valve and a small portion of the cecum were kept with the small bowel. Procurement and transplant techniques were the same as for the retransplant in the first patient, with the portal vein of the recipient having been recanalized by venoplasty. L-IMS was instituted as described for the first patient, but was maintained for 7 weeks.

Two major episodes of acute cellular rejection responded well to the 250-mg boluses of steroids and increased levels of tacrolimus (details in Table 2). One of these two episodes was followed by severe sepsis and pneumonia that required mechanical ventilation for a few days.

The patient was dismissed from the hospital 106 days after transplantation. In spite of two to four bowel movements per day he gained $17 \mathrm{~kg}$ in weight and $7 \mathrm{~cm}$ in height after 1 year posttransplant. His body mass index is $18.8 \mathrm{~kg} / \mathrm{m}^{2}$. Quite striking was the disappearance of bone pain at 3 months and normalization of the spine curves. At 6 months he could play tennis for 1 hour. $\mathrm{He}$ is presently a happy and very successful student.

\section{CONCLUSIONS}

These two particularly difficult cases of SBTx (including an SBTx and a retransplant) in very critical patients show that local intraarterial immunosuppression is feasible in the human when using cadaveric grafts. The technique developed proved to be simple and reliable. No vascular harmful effects resulted from local intraarterial perfusion of any of the drugs used (methylprednisolone, tacrolimus, heparin). The total doses of IMS were lower than those usually practiced in the routine protocol. The rejection episodes under L-IMS were easily controlled. A variety of questions 
remain to be answered about local acute rejection effects, pharmacodynamics, ideal doses, type of infusion (continuous or boluses), etc. However, our preliminary experience suggests that the benefits already shown in animal trials may be realized in humans and deserve future trials.

\section{REFERENCES}

1. Gruber SA: Local Immunosuppression of Organ Transplants. Austin, TX: Springer; 1996

2. Kountz SL, Cohn RR: Surg Forum 18:251, 1967 AQ1: Au: Clear? 